\title{
The Effect of Bisphosphonate [Pamidronate] On Orthodontic Tooth Movement in Rabbits
}

\author{
Venkataramana $\mathrm{V}^{1}$, Rajasigamani $\mathrm{K}^{2}$, Kurunjikumaran $\mathrm{N}^{3}$, Chidambaram ${ }^{4}$ \\ Mohammed Arafath ${ }^{5}$ \\ ${ }^{1}$ Reader [ Ph.D Scholar-Part Time ], 2. Vice-Principal, Professor and head 3. Reader 4.Professor 5. Reader \\ Department of Orthodontics, Faculty of Dentistry, Rajah Muthiah Dental College, Annamalai University, \\ Chidambaram. Tamilnadu, INDIA.
}

\begin{abstract}
OBJECTIVES: The purpose of this study is to investigate the influence of local administration of bisphosphonate i.e.pamidronate (antiresorptive drug), during orthodontic tooth movement in experimental albino Newzealand rabbits. MATERIALS AND METHODS: The current study was conducted on 20 male Newzealand albino rabbits of 3.75 to $4 \mathrm{~kg}$ wt for a period of three weeks (21days). Animals were equally divided into 2 groups [ Group-1 Control \& Group-2 Experimental ].Orthodontic appliance of 100gm force Nitinol closed coil spring was stretched and placed between mandibular molar and incisors in either group of animals. Bisphosphonate [Pamidronate] was injected mesial to the mandibular molar in the mucoperiosteal area. On the last day i.e. $21^{\text {st }}$ day of the study all animals were sacrificed and mandibles were dissected from both groups along with the appliance. The amount of mesial drift of molar was found clearly in the dissected mandibles and measured with flexible manual scale. RESULTS: On $21^{\text {st }}$ day of experiment, both groups of animals were sacrificed and the diastema was measured between $1^{\text {st }}$ and $2^{\text {nd }}$ molar on dissected mandibles. In this study the statistical analysis was done by Student 't'test. The statistical analysis has shown a significant difference between the control $(4.960 \pm 0.455 \mathrm{~mm})$ and the experimental group $(2.389 \pm 0.362 \mathrm{~mm})$. CONCLUSION: The present study was concluded that locally injected bisphosphonate -pamidronate had reduced molar tooth movement in rabbits, this concept may be applicable in near future for the purpose of orthodontic anchorage
\end{abstract}

Keywords: Local injection, Bisphosphonate (Bp), Orthodontic tooth movement (OTM), Rabbit mandibular molar, dissected rabbit mandibles, Pharmacological anchorage

\section{Introduction}

Orthodontic tooth movement [OTM] is a phenomenon where the tooth movement occurs as a reaction towards applied forces due to cellular and molecular responses taken place in the periodontal ligament [PDL] which creates remodeling in the alveolar bone. The applied force produces tension zone (opposite to applied force) and pressure zone (towards applied force). The osteoblasts are responsible for bone formation and osteoclasts are for bone resorption, the tooth movement occurs towards resorption direction ${ }^{1-2}$.

OTM is an event, when a tooth movement taken place; it gets the periodontal ligament and the alveolar socket with it. PDL membrane serves as pericementum for tooth and periosteum for alveolus. It gives shock absorb effect to the tooth root and acts as a source of nutrients which are carried by the circulation. Various medicinal supplements used in animal experiments and consumed by patients are carried to the periodontium by the blood and exhibit their influence during OTM in positive way (promoters of OTM) / negative way (suppressors of OTM). Drugs like Corticosteroids in dose dependant manner ${ }^{[3,4]}$ local application of Vit- $\mathrm{D}_{3}{ }^{[5,6,7}$ ${ }^{1}$,PTH hormones ${ }^{[8,9]}$, Prostaglandins ${ }^{[10]}$,cytokines ${ }^{[11]}$ are considered as promoters of OTM. Drugs like NSAID's indomethacin ${ }^{[12]}$, Acetyl salicylic acid ${ }^{[13,14]}$, ibuprofen ${ }^{[14]}$ and diclofenac sodium ${ }^{[15]}$ etc; are considered as suppressors of OTM.

In the field of orthodontics from the beginning the center of attention has always been on mechanical approaches to enhance anchorage system. These mechanical anchorage preparations - skeletal anchorage by zygomatic ligatures ${ }^{[16]}$, prosthetic implants as anchorage source, ${ }^{[17]}$ palatal implants ${ }^{[18]}$ etc. are still popular all over the world because of their compliance and efficacy in orthodontic treatment outcomes. Even though with all conventional orthodontic anchorage mechanics it is impossible to maintain absolute anchorage in any type of tooth movement. Recently micro mini implants have revolutionized in the field of orthodontics as an effective method to achieve absolute anchorage ${ }^{[19,20]}$ At the same time these implant devices have few drawbacks like poor patient cooperation, minimal damaging anatomical structures, inflammatory changes, questionable success rate etc. To overcome these drawbacks of implants in the future era simple local induction of pharmacological agents to achieve anchorage may became traditional in clinical orthodontic practice. This concept of achieving anchorage by local induction of drugs is termed as "PHARMACOLOGICAL ANCHORGE." [21] 


\section{BISPHOSPHONATES [Bps]}

Bps are a category of drugs acts as antiresorptive agents, which operates against osteoclasts in preventing the bone loss and these are prescribed in various skeletal disorders like Paget's disease, osteogenesis imperfecta, osteoporosis, bone metastasis in malignant conditions etc. Mainly two subclasses of Bps are present, they are Amino Bps (Nitrogenous) and Non-Amino Bps (Non-nitrogenous). Alendronate, neridronate, ibandronate, pamidronate, risedronate, and zoledronic acid are called nitrogen-containing Bps; where as etidronate and tiludronate are called non-nitrogen-containing Bps. The non-amino Bps are less potent than amino Bps. They acts in different path way, but ultimate goal is osteoclast apotosis (killing osteoclast cells) in resorptive areas and prevention of bone loss ${ }^{[22]}$

The unfavorable effects like impeded tooth movement, difficulty in extraction space ${ }^{[23]}$. increase treatment duration were encountered in patients using Bps under orthodontic therapy ${ }^{[24]}$

In contrary, the impediment of tooth movement (unfavorable effect) by Bp can be utilized in orthodontics for establishment of anchorage. In this context few animal experimental studies have been performed by local administration of various drugs including Bps.

In the present study, locally injected pamidronate, has shown significant decreased OTM in experimental Australian albino rabbits which may be beneficial in anchorage point of view.

\section{ANIMALS USED}

\section{Materials And Methods}

This study protocol has been approved by the institutional animal ethical committee (IAEC) Protocol Approval no: 160/1999/CPSEA, Prop.no:854 belongs to Annamalai University, Tamilnadu, India. Total 20 Newzealand albino rabbits used in this study were supplied by animal house of Annamalai University, Annamalai Nagar, Tamilnadu, India. Total '20'animals are divided into 2 groups; group-1 of 10 animals served as control (Appliance + normal saline, No drug) and group- 2 as experimental (Appliance + drug). One week prior to beginning of the study all the animals were fed with proper diet and all animals were at the proper weight of 3.5- 4kgs all the rabbits were kept in individual cage and regular check up has been done by veterinarian staff to monitor the feeding and activity of the animals. The animals were maintained at room temperature between $20^{\circ} \mathrm{C}$ to $25^{\circ} \mathrm{C}$ with constant humidity.

\section{DRUGS, CHEMICALS AND OTHER MATERIALS USED}

Pamidronate (amino Bp) supplied as Biodronate 30mg vial ( Pamidronate Disodium for I.V.infusion by United Biotech Pvt Ltd, India was used as a major drug for evaluating its local effect. Other drugs like Inj.atropine sulphate, Inj.ketamine, Inj.diazepam and Injection potassium chloride were used on animals for anaesthetizing and euthanizing. Other orthodontic materials used for fabrication of the intra oral appliance are ligature wire 0.010 " diameter, NiTi coil spring of 100 gm force, light cure primer and composite (Transbond XT - 3M Unitek), custom made mouth prop with 19 gauge SS wire.

\section{EXPERIMENTAL METHOD}

Total 20 rabbits were segregated into 2 groups, one group of 10 animals served as control (Appliance + normal saline, No drug) and the another group as experimental (Appliance + drug).To reduce the vagal tonus $0.2 \mathrm{mg} / \mathrm{kg}$ atropine sulphate I.M injection is given to all animals. Animals were anesthesized by ketamine $35 \mathrm{mg} / \mathrm{kg}$,bdwt and diazepam $5 \mathrm{mg} / \mathrm{kg}$ bdwt, at this stage animals were ready to receive the appliance. Following anaesthesia, the grooves have been made coronally around the molar and incisors with the help of airotor hand piece under suction device, later etched with $37 \%$ phosphoric acid for 30 seconds around the coronal portions of the molar and incisors including grooves; the etched portion was thoroughly isolated with an airway syringe. The ligature wire (0.010") has passed interdentally between $1^{\text {st }}$ and $2^{\text {nd }}$ molar and wrapped around the $1^{\text {st }}$ molar, similarly ligature wire also tied in figure of eight manner around incisors, and twisted with artery forceps till they fit into the grooves, then niti coil springs were (100gm force) tied to ligature wire between mandibular molar and incisors. The excessive wires were cut with ligature cutter and the ligature wires bent closely towards teeth surfaces to avoid injury to soft tissue. A thin coat of composite 3M Transbond XT primer was applied around the etched surfaces including the grooves filled with ligature wires and cured, later composite Transbond XT (3M Unitek) was applied and light cured in order to avoid dislodgement of the appliance and lessen irritation of any wire projections.( Figure 1 A)

After installation of the appliance each experimental group animal has received $1.5 \mathrm{mg} / 0.5 \mathrm{ml}$ pamidronate locally, mesial to the molar where as each control group animal has received normal saline injection of $2.5 \mathrm{ml}$ with the help of 1 unit insulin syringe on $1^{\text {st }}$ day and $7^{\text {th }}$ day and $14^{\text {th }}$ day of experiment. All animals were observed carefully for the entire experimental period. On $21^{\text {st }}$ day either group of animals were anaesthetized again as described previously and sacrificed by giving $2 \mathrm{ml}$ intra cardiac injection of potassium chloride. The mandibles of all animals were dissected carefully along with $\mathrm{Ni}-\mathrm{Ti}$ coil springs and diastema was 
observed in between $1^{\text {st }}$ molar and $2^{\text {nd }}$ molar with naked eye In experimental group reduced amount of diastema was produced compared to control group, which might be due to execution of anti resorptive activity of locally administered pamidronate against to the tooth movement in the mesial direction. The Ni-Ti coil springs were then removed from the dissected mandibles and the diastema of 40 dissected mandibles were measure from mesial margin of $2^{\text {nd }}$ molar to the distal margin of $1^{\text {st }}$ molar with the help of transparent flexible scale and evaluated the results.

\section{STATISTICAL ANALYSIS}

\section{Results}

The results were reported as mean \pm standard deviation. The student $(t)$ test was used to calculate the difference between two means. The $p$ valve is considered significant if it was less than $0.05(p<0.05)$

The experimental group i.e. locally administered pamidronate animals have shown significant decreased tooth movement when compared to non drug induced control group.

The values obtained from either group of animals after measurement of diastema i.e. the distance between mesial margin of $2^{\text {nd }}$ molar and distal margin of $1^{\text {st }}$ molar were shown clear disparity (Table -1 , Figure-2). The measured mean values obtained from dissected mandibles in either group were statistically evaluated, which has shown a significant difference $(\mathrm{p}<0.001)$ between control and experimental groups, which indicates decreased amount of molars in drug induced group [Table- 2 and Figure- 3].

\section{Discussion}

There are few number of studies have been documented on animal models with administration of Bps related to tooth movement. Keles etal ${ }^{[25]}$, Seifi etal ${ }^{[26]}$, Kim etal ${ }^{[27]}$, Jeremy etal ${ }^{[28]}$, Igarashi et al ${ }^{[21]}$ and Adachi $^{[29]}$ have done various animal experimental studies and reported that Bps cause a reduction in orthodontic tooth movement. The results of present study were similar to those of the earlier studies. However, all previous experimental studies were carried out on rats, mices and very few in rabbits. In this study NewZealand albino rabbits were used because of ease of handling and fabrication of intraoral appliance is comfortable compared to rats and also similarities are reported in the bone mineral density (BMD) and fracture toughness. ${ }^{[30]}$

Bps are widely used to treat bone metabolic disorders. Bp users of orthodontic patients have shown impeded tooth movement, space closure difficulties etc. The undesirable side effect of BPs i.e. impediment of tooth movement may be utilized as desirable effect by local administration to promote "pharmacological anchorage', which is one of the important event in orthodontic treatment plan. The result of the present study is highly recommended that local administration of bisphosphonate [pamidronate] in rabbits led to decrease in orthodontic tooth movement. Two animal groups in this study have shown major dissimilarity in their tooth movement .The significant decreased tooth movement in experimental group was observed probably due to anti resorptive effect/anti osteoclastic effect of bisphosphonate [pamidronate] caused by osteoclastic apoptosis which is a favorable outcome from the anchorage point of view.

An experimental study by Keles etal ${ }^{[25]}$ in mice using pamidronate over a period of eight days and observed inhibition of undesired tooth movement under constant orthodontic force, which has shown similarity with the results of the present study performed in rabbits in preventing molar movement in pamidronate injected animals.

Seifi etal ${ }^{[26]}$ and Kim etal ${ }^{[27]}$ stated that the systemic administration of pamidronate in rats was resulted in reduction of relapse and reduced root resorption which are unfavorable effect during orthodontic tooth movement. Seifi etal also measured the molar movements in rats that revealed the reduction in tooth movement. Similarly in the current study the tooth movement was measured on dissected mandibles and observed impeded tooth movement in drug administered rabbits.

Jeremy etal ${ }^{[28]}$ explained the retarded tooth movement in rats by measuring the distance between first and second molars following oral administration of alendronate. In the current study also the amount of reduced tooth movement was assessed from measurements obtained from dissected mandibles with flexible scale.

Igarashi etal ${ }^{[21]}$ have documented the efficacy of alendronate in impeding tooth movement in rats when given locally for three weeks time. In the present study pamidronate belongs to Nitrogen containing bisphosphonates similar to alendronate showed significant reduction of tooth movement in rabbits for a period of three weeks time.

Adachi etal ${ }^{[29]}$ studied the effect of locally administered bisphosphonate (Risedronate) and concluded that there was a significant reduction of buccal movement of molars in drug induced rats. In the current study pamidronate also has shown similar effect as risedronate in the reduction of tooth movement.

Other than bisphosphonates few medications like NSAID's (Eg. indomethacin ${ }^{[12]}$, Acetyl salicylic acid, ${ }^{[13,14]}$ ibuprofen ${ }^{[14]}$ and diclofenac sodium ${ }^{[15}$ etc.) also impede orthodontic tooth movement when given systemically or locally. These drugs are comparatively less potent then bisphosphonate group because 
The Effect Of Bisphosphonate [Pamidronate] On Orthodontic Tooth Movement In Rabbits bisphosphonates directly possess anti osteoclastic activity where as NSAID's blocks only the part of AA signaling pathway.

\section{Tables, Figures And Legends}

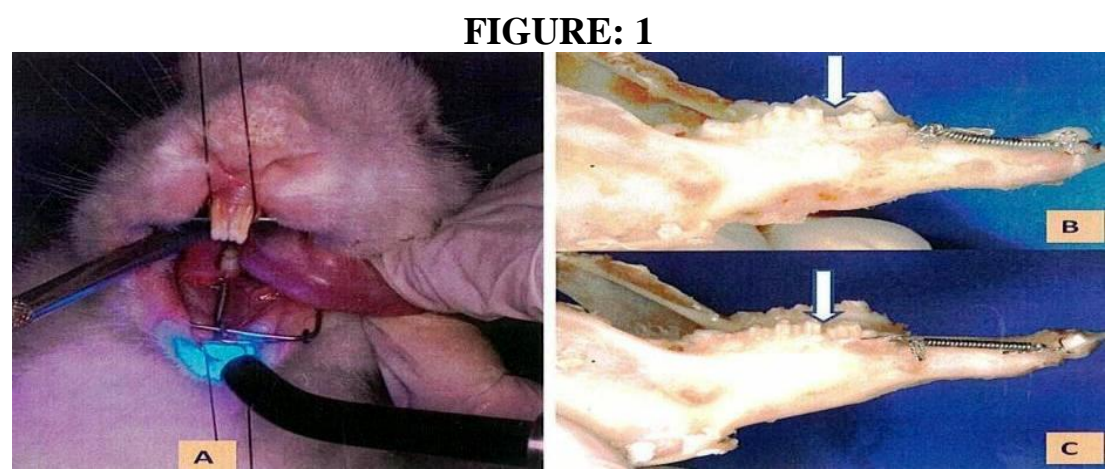

A). Rabbit with appliance insertion B).Control $\mathrm{Gr}$ - dissected mandible shown increased diastema between $1^{\text {st }}$ and $2^{\text {nd }}$ molars ( excess mesial molar drift) $\mathbf{C}$ ).Exp $\mathrm{Gr}$-dissected mandible shown decreased diastema between $1^{\text {st }}$ and $2^{\text {nd }}$ molars ( decreasse mesial molar drift)

TABLE: 1

COMPARISION OF MOLAR TOOTH MOVEMENT (mm's) IN BOTH GROUPS MEASURED ON DISSECTED MANDIBLES.

\begin{tabular}{|c|c|c|}
\hline No. & Control & Experimental \\
\hline 1. & 5.2 & 2.1 \\
\hline 2. & 4.8 & 2.4 \\
\hline 3. & 5.1 & 2.6 \\
\hline 4. & 4.3 & 2.2 \\
\hline 5. & 5.3 & 3.1 \\
\hline 6. & 4.8 & 2.1 \\
\hline 7. & 4.6 & 1.9 \\
\hline 8. & 5.4 & 2.5 \\
\hline 9. & 5.2 & 2.6 \\
\hline 10 & 4.4 & 2.0 \\
\hline
\end{tabular}

FIGURE: 2

COMPARISION OF MOLAR TOOT MOVEMENT (mm's) IN BOTH GROUPS

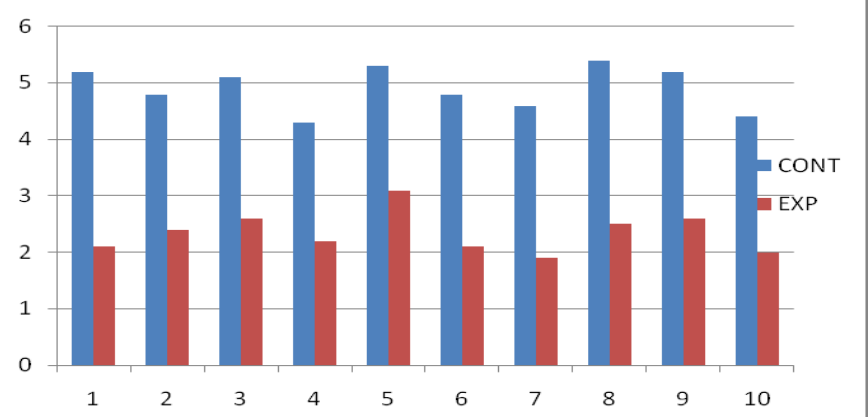

Inference: The mean of the Control group is higher than the Experimental group. 
TABLE: 2

COMPARISION OF MEAN VALUES IN BOTH GROUPS

\begin{tabular}{|c|c|c|c|c|c|}
\hline Groups & $\mathrm{N}$ & Mean & $\begin{array}{c}\text { Std. } \\
\text { Deviation }\end{array}$ & t- value & P-Value \\
\hline Control & 10 & 4.960 & 0.455 & \multirow{2}{*}{14.1654} & 0.001 (Significant) \\
\cline { 1 - 4 } Experimental & 10 & 2.389 & 0.362 & & \\
\hline
\end{tabular}

Inference - From the above table it is inferred that the calculated P-value is significant at 0.001 level (P-Value $<0.001)$. Therefore it is concluded that there is a significant difference between control and Experimental groups.

FIGURE: 3

COMPARISION OF MEAN VALUES OF MOLAR TOOTH MOVEMENT IN BOTH GROUPS

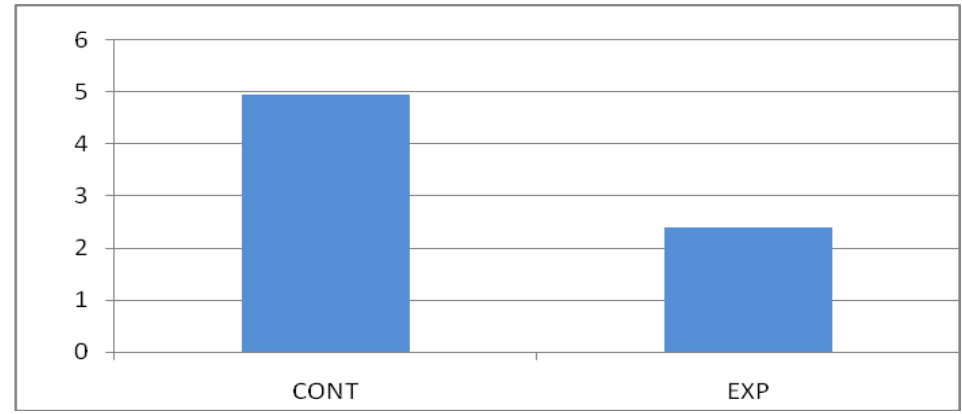

Inference: From the above graph it is inferred that control group (4.960) is higher mean value than the experimental group (2.389).

\section{Conclusion}

The outcome of the present study has clearly demonstrated that the locally injected Bisphosphonate (pamidronate) had influenced OTM in negative way i.e. impediment of tooth movement which might be due to the elicitation of anti resorptive effect of the drug in the injected site which is an enthusiastic finding from orthodontic aspect. This may be beneficial in regards to enhancement of anchorage in orthodontic therapy. Till date, only few basic level studies have been performed in this perspective, which were not quantitative and qualitative. Further numerous experimental studies should accomplish in order to implicate 'pharmacological anchorage system' in human subjects.

\section{References}

[1] Meikle M. The tissue, cellular, and molecular regulation of orthodontic tooth movement: 100 years after Carl Sandstedt. European Jour of Orth 28;2006;:22 1-240

[2] King GJ, Keeling SD, Wronksi TJ. Histomorphometric study of alveolar bone turnover in orthodontic tooth movement. Bone (12) 1991;401-409.

[3] Ashcraft MB, Southard KA, Tolley EA. The effect of corticosteroid- induced osteoporosis on orthodontic tooth movement. Am $J$ Orthod Dentofacial Orthop 102; 1992;:310-9.

[4] Ong CK, Walsh LJ, Harbrow D, Taverne AA, Symons AL. Orthodontic tooth movement in the prednisolone-treated rat. Angle Orthod (70); 2000;:118-25

[5] Kale S, Kocadereli I, Atilla P, Asan E. Comparison of the effects of 1,25 dihydroxycholecalciferol and prostaglandin E2 on orthodontic tooth movement. Am J Orthod Dentofacial Orthop 2004;125:607-14.

[6] Takano-Yamamoto T, Kawakami M, Yamashiro T. Effect of age on the rate of tooth movement in combination with local use of 1,25(OH)2D3 and mechanical force in the rat. J Dent Res 1992;71:1487-92.

[7] Collins MK, Sinclair PM. The local use of vitamin D to increase the rate of orthodontic tooth movement. Am J Orthod Dentofacial Orthop 1988;94:278-84.

[8] Soma S, Matsumoto S, Higuchi Y, Takano-Yamamoto T, Yamashita K, Kurisu K, et al. Local and chronic application of PTH accelerates tooth movement in rats. J Dent Res 2000;79:1717-24.

[9] Soma S, Iwamoto M, Higuchi Y, Kurisu K. Effects of continuous infusion of PTH on experimental tooth movement in rats. $J$ Bone Miner Res 1999;14:546-54.

[10] Yamasaki K, Shibata Y, Fukuhara T. The effect of prostaglandins on experimental tooth movement in monkeys (Macaca fuscata). J Dent Res 1982;61:1444-6.

[11] Laura.r iwasaki etal.Tooth movement and cytokines in gingival crevicular fluid and whole blood in growing and adult subjects Amj Orthod Dentofacial Orthop :2005:128;(483-91) 
[12] Giunta D, Keller J, Nielsen FF, Melsen B. Influence of indometacin on bone turnover related to orthodontic tooth movement in miniature pigs. Am J Orthod Dentofacial Orthop 1995;108: 361-6.

[13] Wong A, Reynolds EC, West VC. The effect of acetylsalicylic acid on orthodontic tooth movement in the guinea pig. Am $J$ Orthod Dentofacial Orthop 1992;102:360-5.

[14] Arias OR, Marquez-Orozco MC. Aspirin, acetaminophen, and ibuprofen: their effects on orthodontic tooth movement. Am $J$ Orthod Dentofacial Orthop 2006;130:364-70.

[15] De Carlos F, Cobo J, Diaz-Esnal B, Arguelles J, Vijande M, Costales M. Orthodontic tooth movement after inhibition of cyclooxygenase-2. Am J Orthod Dentofacial Orthop 2006;129: 402-6.

[16] Melsen B, Petersen J K, Costa A. Zygoma ligatures: an alternative form of maxillary anchorage. J Clin Orthod 1998 Mar;32(3):154-8

[17] Roberts W E. Bone dynamics of osseointegration, ankylosis and tooth movement. J Indiana Dent Assoc 1999 Fall;78(3):24-32.

[18] Sugawara J, Daimaruya T, Umemori M, Nagasaka H, Takahashi I, Kawamura H, Mitani H. Distal movement of mandibular molars in adult patients with the skeletal anchorage system. Am J Orthod Dentofacial Orthop 2004 Feb; 125(2):130-8

[19] Costa A, Raffainl M, Melsen B. Miniscrews as orthodontic anchorage: a preliminary report. Int J Adult Orthod Orthognath Surg 1998;13(3):201-9

[20] Deguchi T, Takano-Yamamoto T, Kanomi R, Hartsfield J K Jr., Roberts W E, Garetto LP.The use of small Titanium Screws for Orthodontic Anchorage. J Dent Res 2003;82(5):377-81

[21] Igarashi K, Mitani H, Adachi H, Shinoda H. Anchorage and retentive effects of a bisphosphonate (AHBuBP) on tooth movement in rats. Am J Orthod Dentofacial Orthop 1994;106:279-89.

[22] Russell RG, 2011. "Bisphosphonates: the first 40 years." Bone 49 (1): 2- 19

[23] Markewicz MR, Margarone JE 3rd, Campbell JH, Aguirre A. Bisphosphonate- associated osteonecrosis of the jaws: a review of current knowledge. J Am Dent Assoc 2005;136:1669-74.

[24] James J. Zahrowski. Optimizing orthodontic treatment in patients taking bisphosphonates for osteoporosis. Am $J$ Orthod Dentofacial Orthop 2009;135:361-74

[25] Keles A, Grunes B, DiFuria C, Gagari E, Srinivasan V, Darendeliler MA, et al. Inhibition of tooth movement by osteoprotegerin vs. pamidronate under conditions of constant orthodontic force. Eur J Oral Sci 2007;115:131-6.

[26] Seifi M, . Aghaeei Pour N. Effect of Pamidronate on tooth movement and root resorption in rat. Shahid Beheshti Univ. Dent. J 2009;27(2).

[27] Kim TW, Yoshida Y, Yokoya K, Sasaki T. An ultrastructural study of the effects of bisphosphonate administration on osteoclastic bone resorption during relapse of experimentally moved rat molars. Am J Orthod Dentofacial Orthop 1999;115:64553

[28] Jeremy C. Karras, James R. Miller, James S. Hodges, John P. Beyer, and Brent E. Larson. Effect of alendronate on orthodontic tooth movement in rats . Am J Orthod Dentofacial Orthop 2009;136:843-7

[29] H. Adachi, K. Igarashi, H. Mitani and H. ShinodaJ. Effects of Topical Administration of a Bisphosphonate (Risedronate) on Orthodontic Tooth movement.. Dent Research 1994; 73; 1478

[30] Wang X, Mabrey JD, Agarwal CM (1998) An interspecies comparision of bone fracture properties. Biomed Mater Eng 8: 1-9. 